\title{
Impactos do Projeto de Lei no 7.920/2017 nos processos de gestão documental nos arquivos brasileiros: reflexões e posicionamentos
}

\author{
Impacts of Bill 7,920/2017 on document management processes in Brazilian archives: re- \\ flections and positions
}

\author{
Claudialyne da Silva Araújo \\ Doutora em Ciência da Informação \\ Universidade Estadual da Paraíba \\ claudialynearaujo@gmail.com \\ Monica de Paiva Santos \\ Doutoranda em Ciência da Informação \\ Universidade Federal da Paraíba \\ nicpaiva@gmail.com \\ Danielle Alves de Oliveira \\ Doutoranda em Ciência da Informação \\ Universidade Federal da Paraíba \\ daniellealvs@gmail.com
}

\begin{abstract}
Resumo
Nos últimos anos, debates acerca do Projeto de Lei $n^{\circ} 7.920 / 2017$ têm polemizado sobre a digitalização de documentos e seus efeitos. O referido Projeto prevê, em síntese, a eliminação do documento físico a partir da digitalização. Essa pesquisa tem como objetivo refletir sobre os impactos do PL 7.920/2017 na Gestão Documental. Metodologicamente, a pesquisa tem natureza exploratória e descritiva com abordagem qualitativa, tendo como sujeitos docentes dos cursos de Arquivologia da Universidade Estadual da Paraíba e da Universidade Federal da Paraíba. Como instrumento de coleta de dados, optou-se pelo questionário com dez perguntas abertas que foi aplicado com os docentes. Como resultados alcançados, constataram-se as fragilidades do PL 7.920/2017, que não contempla os elementos essenciais de digitalização e preservação digital, pontuando a eliminação do documento analógico, mas desconsidera os órgãos nacionais e internacionais de arquivo e os instrumentos de gestão essenciais no tratamento documental.
\end{abstract}

\section{Palavras-chave}

Digitalização de documentos. Gestão Documental. Gestão Eletrônica de Documentos. PL 7.920/2017. Políticas de Preservação Digital.

\begin{abstract}
In recent years, debates about Bill No. 7,920 / 2017 have been controversial about the digitization of documents and their effects. The aforementioned Project foresees, in summary, the elimination of the physical document from digitalization. This research aims to reflect on the impacts of $P L 7,920$ / 2017 on Document Management. Methodologically, the research has an exploratory and descriptive nature with a qualitative approach, with teaching subjects from the Archivology courses at the State University of Paraiba and the Federal University of Paraiba. As a data collection instrument, we chose the questionnaire with ten open questions that was applied with the teachers. As results achieved, the weaknesses of $P L$ 7,920 / 2017 were found, which does not include the essential elements of digit-
\end{abstract}


ization and digital preservation, punctuating the elimination of the analogue document, but disregards the national and international archiving bodies and the essential management instruments in the documentary treatment.

\section{Keywords}

Document Scanning. Document management. Electronic Document Management. PL 7,920 / 2017. Digital Preservation Policies.

\section{INTRODUÇÃO}

Questões acerca de inserções tecnológicas como soluções ao problema do acúmulo documental nos arquivos têm adquirido cada vez mais força em ambientes organizacionais e acadêmicos. Temáticas como curadoria, preservação, gestão e políticas digitais têm elevado as discussões arquivísticas acerca de apontamentos teóricos e práticos. Neste cenário, debates acerca do Projeto de Lei (PL) no 7.920/17 foram iniciadas no Senado Federal como PLS no 146/2007, que foi arquivado e anos depois seguiu para a Câmara dos Deputados como PLC no 7.920/2017, intitulado entre os especialistas da área como o projeto da "Queima de Arquivo".

O referido Projeto prevê, em síntese, a eliminação do documento físico a partir da digitalização, como forma de minimizar os problemas com a gestão e, assim, viabilizar o acesso rápido e diminuir os custos com espaço físico para a guarda. Entretanto, lacunas existentes no corpo do texto do PL têm desencadeado vários debates por parte dos Arquivistas sobre a eliminação indiscriminada dos documentos físicos, pautada em critérios frágeis de elementos que não, necessariamente, garantem preservação e autenticidade dos documentos.

Nessa perspectiva, esse artigo objetiva refletir sobre os impactos do PL $\mathrm{n}$ 응 $7.920 / 2017$ na gestão documental e, de modo mais específico, apresentar o processo de Gestão Documental com base nas teorias arquivísticas. Ademais, visa discutir o PL, apresentando as lacunas existentes e o posicionamento de profissionais da área, frente aplicabilidade da lei. Vale salientar que, desde o final do ano de 2017, a discussão em torno do Projeto de Lei que está "paralisada", todavia, pode voltar ao centro da discussão política, a qualquer momento, visto que o atual presidente já deu sinais favoráveis à aprovação na forma da Lei Federal no 13.874/2019 (BRASIL, 2019).

\section{A GESTÃO DOCUMENTAL NAS ORGANIZAÇÕES PÚBLICAS}

Um arquivo público é estabelecido como uma instituição encarregada de armazenar, manter, conservar e prover acesso ao conjunto de documentos produzidos ou recebidos por instituições governamentais ou particulares em virtude de suas funções específicas.

Tais instituições possuem grandes acervos documentais de valor histórico, cultural, legal e probatório. São documentos permanentes, originais e únicos, muitas vezes, já fragilizados pela ação do tempo ou pela falta de políticas de preservação e conservação. Entretanto, mesmo com esse cenário, são essenciais para a ressignificação da memória social e para consubstanciar a tomada de decisão em diversas áreas.

Após meados do século XX, a produção de documentos cresce a níveis muito elevados, que superaram, em muito, a capacidade de controle e organização das empresas. Nesse

\footnotetext{
${ }^{1}$ Está aguardando encaminhamentos na Câmara dos Deputados, após aprovação no Senado, em junho de 2017.
} 
sentido, essas instituições passaram a buscar estratégias para resolver o problema com a massa documental acumulada.

Considerando o contexto tecnológico e informacional em que estamos inseridos, a Gestão Documental vem se mostrando um caminho eficiente e seguro para melhor organização e credibilidade dos documentos; sua implementação torna-se cada vez mais necessária nas organizações, bem como a contratação de um arquivista para executar todas as ações necessárias dentro da instituição. A informação é o maior tesouro da empresa e deve ser tratada como algo valioso.

De acordo com o Dicionário Brasileiro de Terminologia Arquivística, gestão de documentos é:

Conjunto de procedimentos e operações técnicas referentes à produção, tramitação, uso, avaliação e arquivamento de arquivamento de documentos em fase corrente e intermediária, visando sua eliminação ou recolhimento. Também chamado administração de documentos. (ARQUIVO NACIONAL, 2005, p. 100, grifos do autor).

As vantagens da implementação da gestão documental são imensas, visto que o processo deve ser iniciado desde a produção documental, ou seja, possibilita uma racionalização no que é produzido e recebido. Além disso, com a gestão de documentos, observa-se maior segurança informacional, organização e recuperação da informação. Deste modo, evita-se o acúmulo desordenado e a guarda de documentos que não possuam valor para a instituição.

Assim, ao se propor um trabalho de gestão documental, é necessário, antes de qualquer iniciativa, conhecer bem a instituição, bem como ter critérios que ajudem a selecionar o método mais apropriado à realidade pretendida, reconhecer o melhor momento para sua aplicação. Portanto, o processo de gestão não se reduz somente a evitar a produção de documentos inúteis e constituir depósitos para garantir a organização e a preservação dos documentos. A gestão abrange todas as operações referentes à produção, à tramitação, ao uso, à avaliação e ao arquivamento.

Conforme afirma Bernardes e Delatorre (2008, p. 7), “[...] um programa de gestão documental deverá definir normas e procedimentos técnicos referentes à produção, tramitação, classificação, avaliação, uso e arquivamento dos documentos durante todo o seu ciclo de vida [...]", otimizando os requisitos necessários para promover o acesso e o uso da informação, facilitando o desenvolvimento de sistemas de informação eficazes ao processo de gestão da informação.

Portanto, a gestão documental implica no estudo aprofundado sobre a produção documental do organismo produtor, possibilitando a identificação dos tipos documentais produzidos e recebidos, a definição do tempo de guarda e eliminação dos documentos da organização. É válido lembrar que cada organização, seja ela pública ou privada, deve ter seu sistema de gestão específico adequado à instituição, com base nos instrumentos de gestão e controle, o plano de classificação e tabela de temporalidade, que simplifica e racionaliza o montante documental que é gerado diariamente nas instituições (SANTOS, 2014).

Logo, com a implantação de um sistema de gestão adequado, as organizações passam a ter um fluxo documental mais eficiente, evitando danos e o acúmulo desordenado de documentos. Assim, a gestão documental não só atende aos interesses imediatos do produtor ou dos seus usuários, como também contribui para a preservação da memória, pois, o direito ao acesso à informação e a memória caminham juntos. 
A gestão de documentos nos arquivos não pode ser entendida como sinônimo do gerenciamento de informações de conteúdo dos documentos. Apenas o conteúdo informativo de documentos eletrônicos é insuficiente para a identificação dos dados contextuais de proveniência arquivística.

Com o constante crescimento no volume de documentos, se faz necessária a pesquisa para o desenvolvimento de novos suportes e técnicas para arranjo, armazenamento e disponibilização de documentos. Dentre os mais utilizados, podemos destacar o Gerenciamento Eletrônico de Documentos.

Percebe-se que, com o avanço das tecnologias de informação, existe forte preocupação com os softwares e máquinas que possam facilitar o acesso à informação, porém, se faz necessário conhecer as necessidades informacionais dos usuários que realizarão a pesquisa dessa documentação, fazer seleção através de assunto, datas, tipos de documentos, preparar todos os espaços físicos, mobiliários, ou seja, trabalhar manualmente todos os documentos para, posteriormente, pesquisar um software que seja adequado ao que foi planejado primeiro manualmente (ARAÚJO, 2016).

Ou seja, apenas as tecnologias não garantem preservação, acesso e uso da informação, mas uma gestão competente que vislumbre todos os processos inseridos no sistema de informação completo. De nada adiantaria, por exemplo, copiar eletronicamente - e gerenciar - todos os dados de fichas de funcionários a fim de economizar espaço de arquivamento, se o controle dos códigos de validação dos documentos originais não for feito. Deste modo, "A tecnologia desempenha papel de destaque na era do conhecimento, através da adoção de técnicas e métodos que facilitem os processos de gestão [...]". (ANGELONI, 2002).

Conforme destaca Fachin (2010, p. 35), "O sistema GED [Gestão Eletrônica de Documentos] facilita a busca, o acesso e o armazenamento da informação, como também tem a função de preservar e conservar a massa documental, garantindo que o original, em papel, continue intacto por muitos anos [...]", permitindo que os documentos sejam acessados sempre que requisitado sem causar danos aos originais, bem como possibilita a gestão documental eletrônica e em papel se integrem em um único sistema de informação.

É vital a manutenção das bases de informação e conhecimento nas empresas, e, para isso, temos a política de Preservação Digital, que institucionaliza e padroniza os processos, colocando-os dentre de parâmetros que serão definidos segundo a cultura institucional (KOCH, 1997).

[...] uma política de preservação digital deve ser planejada de acordo com a missão de uma empresa ou de acordo com a política administrativa de uma instituição. No caso das instituições públicas, esse tipo de política tem como objetivo o de implementar ações de preservação dos acervos digitais, de modo que se mantenha o acesso permanente sob a égide da lei de acesso à informação. (SILVA JÚNIOR; MOTA, 2012, p. 53).

Ao pensar em elaborar uma política de preservação, é importante que a equipe seja multidisciplinar e todos os profissionais se articulem em equipe com o objetivo de reforçar a política. Grácio (2012) caracteriza os aspectos da preservação digital em três grupos: organizacional, legal e técnico. Estes grupos possuem forte relação de interdependência, a despeito das suas características intrínsecas, e devem ser tratados conjuntamente num modelo de gestão ou de política de preservação digital.

Apesar dos benefícios da implementação da GED, os documentos originais devem ser preservados, para garantir a originalidade das informações e por serem documentos únicos e carregados de informações relevantes em seu suporte informacional. Ademais, a tecnolo- 
gia ainda é muito frágil e permite a ocorrência de vários riscos, tais como falsificação perfeita de documentos, eliminação acidental (ou intencional), obsolescência tecnológica e vírus diversos.

\section{PL 7.920/2017: LACUNAS E FRAGILIDADES}

A primeira tentativa de aprovar uma lei foi apresentada a partir do PLS no 146/2007, que estabelecia a destruição de documentos originais após sua digitalização. Esse provocou um manifesto de entidades representativas e classes profissionais que levantaram a questão que tal aprovação da Lei poderia colocar em dúvida a autenticidade de documentos públicos, impossibilitando futura verificação no caso de suspeita de fraudes. Assim, o PL vem tramitando há dez anos, e no decorrer dos anos vem mobilizando os profissionais como Arquivistas, Bibliotecários e Historiadores, dentre outros, que exigem o arquivamento definitivo do PL no 7.920/2017, conhecida, nas comunidades acadêmicas e profissionais, como "Lei da Queima de Arquivo".

O PL no 7.920/2017, criado pelo senador Magno Malta, em sua essência legaliza a eliminação de documentos arquivísticos originais, após sua digitalização e arquivamento em mídia ótica ou eletrônica, seja por "[...] incineração, destruição mecânica ou por qualquer outro procedimento que assegure a desintegração do documento [...]" (BRASIL, 2017), sem apresentar discussões com as classes profissionais que trabalham diretamente com gestão documental arquivística e com o resguardo da memória e identidade da sociedade brasileira.

O PL foi sendo aprovado nas instâncias superiores contendo falhas graves em sua redação. Os fragmentos do texto não são suficientes para garantir a preservação dos documentos digitalizados, e assim tornando a eliminação do original um "atentado" à memória social/histórica da sociedade brasileira como também um desrespeito a órgãos e instituições, como o Arquivo Nacional (AN), o Conselho Nacional de Arquivo (CONARQ) e o ConseIho Internacional de Arquivos (CIA), que definem, há décadas, as políticas nacionais de arquivos com base nas legislações nacionais e internacionais.

Em essência, o PL desconsidera a política adotada para os arquivos institucionais, com base nas três idades, arquivo corrente, intermediário e permanente, e, consequentemente, fere a aplicabilidade da tabela de classificação e da tabela de temporalidade. A primeira, de acordo com Faria (2006, p. 35), "[...] é o instrumento de gestão que organiza, em um plano intelectual, os tipos documentais produzidos e/ou recebidos [...]"; enquanto a segunda é o instrumento/meio a partir do qual se determina o prazo de permanência de um documento em um arquivo e sua destinação após este prazo.

Deste modo, os prazos de guarda para os documentos correntes, intermediários e permanentes passam a ser inexistentes no tocante institucional, visto que o PL assevera que o documento não destinado à guarda permanente poderá ser eliminado quando for digitalizado. Deste modo, a eliminação se torna irresponsável e sem nenhum critério administrativo/jurídico que resguarde a instituição e o profissional. Assim, o texto do PL ignora possíveis desastres digitais que viessem a acontecer e, com a inexistência do original, os documentos digitalizados estariam perdidos sem condições de serem recuperados.

$\mathrm{O}$ texto do PL desvaloriza os elementos diplomáticos que constituem o documento analógico e que garante a autenticidade do documento digitalizado; rejeita as normas de gestão documentais e digitais já existentes; desrespeita as classes profissionais que trabaIham em prol da gestão, preservação, conservação, restauração e da memória institucional, em especial os Arquivistas; rejeita a previsão de planejamento e investimentos constantes e 
custos elevados com a manutenção do ambiente tecnológico ao longo dos anos (CONARQ, 2017).

Deste modo, percebem-se as fragilidades do PL e constata-se que o texto não passou por discussões nem apreciações com profissionais devidamente capacitados para intervir na elaboração, e, assim, auxiliar nos processos e políticas de preservação digital com foco na digitalização dos documentos e parâmetros que as compõem.

Desde que foi proposto, o PL no 7.920/2017 (antigo PLS 146/2007), vem causando polêmica entre os profissionais da informação, especialmente entre a classe arquivística. Hott e Cruz-Riascos (2018) destacam que 93\% dos pesquisados são contra a proposta desse $\mathrm{PL}$ e pedem o arquivamento da mesma. Essa reação é motivada pelos riscos que esse instrumento normativo, caso seja aprovado, representa para a sociedade brasileira de um modo geral.

Como já foi dito anteriormente, trata-se de um $\mathrm{PL}$, de autoria do senador Magno Malta (PR-ES), que, em linhas gerais, propõe a eliminação de documentos originais após serem digitalizados e certificados por órgãos competentes. Além disso, a lei específica que "O documento digitalizado terá o mesmo valor legal que o documento que the deu origem" (BRASIL, 2017).

Diante da polêmica, surgiu o movimento contra o PL da "queima de arquivo", que reúne profissionais da Arquivologia e representantes da sociedade civil, com o objetivo de impedir a aprovação desse PL. Esse movimento deu origem a vários espaços de manifestações como blogs e páginas nas redes sociais.

Diante da inviabilidade de abarcar, para este artigo, os conteúdos de todas as redes midiáticas com esse propósito, elegemos o blog "queimadearquivonao", por reunir várias moções de repúdio de importantes entidades do meio acadêmico e científico, especialmente da área arquivística, a partir dos quais destacamos alguns fragilidades, lacuna e aspectos negativos do PL em questão, No Quadro 1.

Quadro 1 - Posicionamento das principais entidades acadêmicas, científicas e técnicas

\begin{tabular}{|c|c|}
\hline Entidades & Aspectos negativos no PL no 7.920/2017 \\
\hline $\begin{array}{l}\text { Conselho Nacional de } \\
\text { Arquivos (CONARQ). }\end{array}$ & $\begin{array}{l}\text { - Possui equívocos ao alterar importantes dispositivos legais sem o amplo de- } \\
\text { bate. } \\
\text { - Extingue a função genuína de "prova” e/ou “testemunho" de grande parte } \\
\text { dos documentos arquivísticos. } \\
\text { - Contraria diversas Resoluções do CONARQ que orientam as práticas de Ges- } \\
\text { tão Documental (GD) implementadas no Brasil. } \\
\text { - Ignora conhecimentos provenientes de pesquisas desenvolvidas no âmbito } \\
\text { da Arquivologia, da Diplomática, do Direito, no cenário nacional e internacio- } \\
\text { nal. } \\
\text { - Apresenta confusão entre autenticação e autenticidade. } \\
\text { - Compreensão equivocada da digitalização como alternativa viável de preser- } \\
\text { vação e da assinatura digital/certificado digital como elemento garantidor da } \\
\text { autenticidade do documento. } \\
\text { - Vago quanto aos documentos produzidos pelas organizações civis, retirando } \\
\text { do poder público a sua autoridade em determinar a manutenção de documen- } \\
\text { tos necessários à fiscalização e controle do estado. } \\
\text { - Retoma em sua redação a tentativa de tornar vigentes artigos da Lei no } \\
12.683 / 2012 \text { e que foram vetados e ainda não apreciados pelo parlamento. }\end{array}$ \\
\hline
\end{tabular}

Fonte: Queima de arquivo não (2019) 
Impactos do Projeto de Lei no 7.920/2017 nos processos de gestão documental nos arquivos brasileiros: reflexões e posicionamentos

Quadro 1 - Posicionamento das principais entidades acadêmicas, científicas e técnicas

(continuação/continua)

\begin{tabular}{|c|c|}
\hline Entidades & Aspectos negativos no PL no 7.920/2017 \\
\hline $\begin{array}{l}\text { Participantes do } 270 \\
\text { Congresso Brasileiro de } \\
\text { Biblioteconomia, Do- } \\
\text { cumentação e Ciência } \\
\text { da Informação. } \\
(19 / 10 / 2017)\end{array}$ & $\begin{array}{l}\text { - Desconsidera todo o arcabouço teórico e prático de instituições e dos profissionais da } \\
\text { área de Arquivologia e afins. } \\
\text { - Contém uma obscura, temerosa e preocupante interpretação para a destruição de } \\
\text { documentos originais. } \\
\text { - Traz em seu bojo uma óbvia demonstração do desconhecimento dos procedimentos } \\
\text { adotados para a preservação de documentos. } \\
\text { - Demonstra também o descaso e a pouca importância dada à memória histórica da } \\
\text { nação. } \\
\text { - Suspeita-se que este tipo de projeto, serve apenas a um crescente ramo de empresá- } \\
\text { rios da área tecnológica, que vê na digitalização de documentos tão somente uma } \\
\text { nova forma de auferir grandes lucros. }\end{array}$ \\
\hline $\begin{array}{l}\text { Sindicato dos Trabalha- } \\
\text { dores em Educação da } \\
\text { Universidade Federal } \\
\text { Fluminense (SINTUFF). }\end{array}$ & $\begin{array}{l}\text { - Sem a mínima preocupação com a definição de políticas de preservação dos mesmos } \\
\text { pelo tempo necessário. } \\
\text { - Sem falar em outras questões - autenticidade, avaliação, temporalidade, terminolo- } \\
\text { gia, certificação digital, valor secundário, conceitos arquivísticos etc. - abordadas por } \\
\text { estudiosos da área de documentação digital aplicada à Arquivologia. }\end{array}$ \\
\hline $\begin{array}{l}\text { Colegiado e a Coorde- } \\
\text { nação do Curso de } \\
\text { Arquivologia do Centro } \\
\text { de Ciências Sociais e } \\
\text { Humanas da Universi- } \\
\text { dade Federal de Santa } \\
\text { Maria. } \\
(29 / 06 / 2017)\end{array}$ & $\begin{array}{l}\text { - Sua aprovação é um retrocesso perigoso para as questões que envolvem prova e } \\
\text { testemunho de arquivos, em especial aqueles que contêm documentos públicos. } \\
\text { - A preservação da memória nacional ficará comprometida caso entre em vigor o refe- } \\
\text { rido PL. } \\
\text { - Urgente a sua retirada de pauta e uma ampla discussão da comunidade arquivística e } \\
\text { das demais áreas que trabalham com memória no País. }\end{array}$ \\
\hline $\begin{array}{l}\text { Encontro Nacional de } \\
\text { Arquivos e Acervos } \\
\text { Audiovisuais Brasileiros. } \\
\text { (26/06/2017) }\end{array}$ & $\begin{array}{l}\text { - Trata-se de uma ameaça à preservação de longo prazo, à transparência pública, à } \\
\text { memória e aos direitos de todos os cidadãos. }\end{array}$ \\
\hline $\begin{array}{l}\text { Sindicato dos Trabalha- } \\
\text { dores do Judiciário } \\
\text { Federal no Rio Grande } \\
\text { do Sul (Sintrajufe/RS). } \\
(24 / 06 / 2017)\end{array}$ & - O atual PL 7.920/17 deve ser barrado para a defesa da memória nacional. \\
\hline $\begin{array}{l}\text { Associação Brasileira de } \\
\text { Pesquisadores em His- } \\
\text { tória Econômica (AB- } \\
\text { PHE). } \\
(06 / 06 / 2017)\end{array}$ & $\begin{array}{l}\text { - A destruição de arquivos deve ser desencorajada. } \\
\text { - O projeto prevê a permissão de que empresas privadas e cartórios assumam o pro- } \\
\text { cesso de digitalização, contudo, não especifica qualquer pré-requisito técnico para sua } \\
\text { realização que represente salvaguardas para a adequada gestão e preservação de } \\
\text { documentos arquivísticos. } \\
\text { - Não se estabelece, adicionalmente, qualquer reflexão sobre as condições para a } \\
\text { guarda do material digitalizado, que exige ambiente tecnológico e custos de preserva- } \\
\text { ção. }\end{array}$ \\
\hline $\begin{array}{l}\text { Delegado(a)s presentes } \\
\text { ao } 36 \text { o-Congresso do } \\
\text { ANDES-SN }\end{array}$ & $\begin{array}{l}\text { - Destruir a garantia de autenticidade das informações registradas, extinguindo, por } \\
\text { completo, a possibilidade de aferir a autenticidade do documento digitalizado, caso se } \\
\text { levante a hipótese de alterações indevidas. } \\
\text { - Qualquer problema de ordem técnica, que atinja as cópias digitalizadas, tornará } \\
\text { irrecuperáveis as informações constantes dos registros originais, caso tenham sido } \\
\text { destruídos. }\end{array}$ \\
\hline $\begin{array}{l}\text { Executiva Nacional dos } \\
\text { Estudantes de Arquivo- } \\
\text { logia. } \\
\text { (Gestão 2016/2017) }\end{array}$ & $\begin{array}{l}\text { - Este PLS é um risco ao acesso à informação e à transparência dos atos públicos. } \\
\text { - Como consequências também, e não só, causará a perda de informações importantes } \\
\text { no contexto de produção de documentos administrativos, em qualquer instituição } \\
\text { pública ou privada. }\end{array}$ \\
\hline
\end{tabular}

Fonte: Queima de arquivo não (2019). 
Quadro 1 - Posicionamento das principais entidades acadêmicas, científicas e técnicas

(continuação)

\begin{tabular}{|c|c|}
\hline Entidades & Aspectos negativos no PL no 7.920/2017 \\
\hline $\begin{array}{l}\text { Associação dos Servi- } \\
\text { dores do Arquivo Na- } \\
\text { cional (ASSAN). }\end{array}$ & $\begin{array}{l}\text { - O projeto tem pelo menos três graves problemas: } \\
\text { - O primeiro é a questão da segurança - não há garantia nenhuma que o su- } \\
\text { porte digital seja uma maneira segura de armazenamento de informações, le- } \\
\text { vando-se em conta a obsolescência dos formatos digitais proprietários e das } \\
\text { mídias; } \\
\text { - A segunda questão é relativa à autenticidade do documento - a digitalização } \\
\text { prevista no projeto ignora esses fundamentos (da Arquivologia e da Diplomá- } \\
\text { tica) e confere à certificação digital uma falsa ideia de autenticidade e despre- } \\
\text { za a possibilidade real de adulterações nos documentos digitais; } \\
\text { - A terceira e mais grave questão - a justificativa de que se faz necessário di- } \\
\text { minuir a quantidade de documentos para que se possa economizar na guarda } \\
\text { e preservação dos mesmos. Isso é uma falácia. O armazenamento de docu- } \\
\text { mentação digital é tão ou mais custoso do que dos documentos analógicos. } \\
\text { - Essa é mais uma medida neoliberal do processo de desmanche do Estado plane- } \\
\text { jado pelo governo Temer. } \\
\text { - O PLS no 146/2007 pretende privatizar os procedimentos de reprodução, auten- } \\
\text { ticação e certificação de documentos públicos, uma vez que empresas privadas e } \\
\text { cartórios seriam credenciados para realizar essas atividades, o que fere a Lei de } \\
\text { Arquivos e atenta contra o papel do Arquivo Nacional e demais instituições custo- } \\
\text { deadoras de documentos. }\end{array}$ \\
\hline $\begin{array}{l}\text { Fórum Nacional de } \\
\text { Ensino e Pesquisa em } \\
\text { Arquivologia (FE- } \\
\text { PARQ). }\end{array}$ & $\begin{array}{l}\text { - O projeto em tela apresenta equívocos graves, entre eles: } \\
\text { - a compreensão da assinatura digital/certificado digital como elemento ga- } \\
\text { rantidor da autenticidade do documento; } \\
\text { - a confusão entre autenticação e autenticidade; } \\
\text { - a compreensão da digitalização como alternativa viável de preservação. } \\
\text { - Representa um retrocesso às práticas arquivísticas implementadas no país e um } \\
\text { prejuízo à sociedade brasileira. }\end{array}$ \\
\hline $\begin{array}{l}\text { Grupo de pesquisa } \\
\text { CNPq UFSM GED/A, } \\
\text { responsável por de- } \\
\text { senvolver pesquisas } \\
\text { em Gestão Arquivística } \\
\text { de Documentos Digi- } \\
\text { tais e Preservação } \\
\text { Digital. } \\
(29 / 11 / 2016)\end{array}$ & $\begin{array}{l}\text { - Destruir o original significa destruir a autenticidade do documento. } \\
\text { - Implica em uma tentativa de destruir os sólidos referenciais e princípios da Ar- } \\
\text { quivística e da Diplomática, colocando em risco os elementos de fixidez que garan- } \\
\text { tem a presunção de autenticidade dos documentos. } \\
\text { - Outro fator que merece menção é o recorrente equívoco de citar o uso da assi- } \\
\text { natura digital/certificado digital como elemento garantidor da autenticidade do } \\
\text { documento. } \\
\text { - Percebe-se que há uma visão imediatista, que pela ânsia de "eliminar o suporte } \\
\text { papel", desconsidera preceitos da gestão documental, da preservação de longo } \\
\text { prazo, além é claro, da presunção de autenticidade dos documentos. }\end{array}$ \\
\hline
\end{tabular}

Fonte: Queima de arquivo não (2019).

A partir dos posicionamentos dessas entidades, constata-se que a grande maioria da classe é contra o PL no 7.920/2017, principalmente, da forma como foi proposta, com pouco ou nenhum debate mais amplo com a classe arquivística.

Outro aspecto considerado preocupante é que esse projeto permite que empresas privadas e cartórios realizem a digitalização e a certificação de documentos públicos sem especificar pré-requisitos técnicos, o que não garante a segurança nem reduz gastos, visto que essas operações envolvem altos custos, podendo onerar ainda mais os gastos públicos (ABECIN, 2017).

Com todas essas questões postas acima, fica evidente as fragilidades e lacunas do PL 7.920/2017, a qual "[...] apresenta graves ameaças à transparência pública, à gestão e preservação dos documentos e da memória." (ABECIN, 2017), o que justifica o pedido de arqui- 
vamento desse projeto por parte das entidades, evitando, assim, um retrocesso para a área arquivística e um prejuízo quanto ao passado, presente e futuro da sociedade brasileira.

\section{PROCEDIMENTOS METODOLÓGICOS}

Metedologicamente, a pesquisa caracteriza-se por uma abordagem qualitativa de natureza exploratória e descritiva, pois visa proporcionar uma visão geral de um determinado fato e procurar padrões, como também apresentar detalhes acerca do fenômeno estudado. Do ponto de vista de Cruz e Ribeiro (2004), a pesquisa exploratória estabelece critérios, métodos e técnicas para elaborar uma pesquisa.

Para alcançar os objetivos da pesquisa, foi elaborado um questionário com perguntas abertas que foram aplicados a quatro docentes, sendo dois do curso de Arquivologia da Universidade Estadual da Paraíba (UEPB) e dois do curso de Arquivologia da Universidade Federal da Paraíba (UFPB). Tais professores foram escolhidos intencionalmente, por apresentarem, em seus perfis profissionais, conhecimento e experiência na área de gestão em documentos digitais e preservação documental. Os sujeitos da pesquisa foram identificados pela letra inicial da palavra "Docente" e o algarismo arábico indicando a ordem de participação, resultando em D1, D2, D3 e D4, visando manter o sigilo e imparcialidade dos docentes.

O questionário foi composto de dez perguntas divididas em três blocos, são eles: Gestão Documental (Quadros 2 a 4), PL no 7.920/2017 (Quadros 5 a 9) e posicionamento dos docentes sobre o PL $n$ o 7.920/2017 (Quadros 10 a 11). Os dados foram analisados e discutidos com base nos referenciais teóricos acima abordados.

\section{RESULTADOS DA PESQUISA}

Conforme fora mencionado, a pesquisa foi realizada por meio de questionário com perguntas abertas, onde os docentes apresentaram a sua opinião no que tange ao PL no 7.920/2017 e o impacto no processo de Gestão Documental.

Deste modo, iniciamos o primeiro bloco de perguntas referente à Gestão Documental, conforme Quadro 2.

Quadro 2 - Processo da gestão documental na arquivística

(continua)

\begin{tabular}{|c|l|}
\hline Docente & \multicolumn{1}{c|}{ Entendimento } \\
\hline D1 & $\begin{array}{l}\text { A gestão arquivística é fundamental para a organização dos acervos em qualquer instituição, } \\
\text { visto que pensa racionalmente o fluxo informacional. Os documentos passam por fase corren- } \\
\text { te, intermediaria e permanente de acordo com a frequência de uso. }\end{array}$ \\
\hline \multirow{5}{*}{ D2 } & $\begin{array}{l}\text { A gestão documental é um procedimento que abrange diversas etapas. Inicia-se com o diag- } \\
\text { nóstico para levantamento de informações com a finalidade de produzir os instrumentos da } \\
\text { gestão: o plano de classificação e a tabela de temporalidade. Neste aspecto é indispensável a } \\
\text { participação da Comissão Permanente de Avaliação que estabelecerá os prazos para as séries } \\
\text { documentais. Além disso a gestão determina as especificações para os documentos na fase } \\
\text { corrente e intermediária, permitindo um fluxo contínuo sem 'gargalos' para que os documen- } \\
\text { tos possam circular sabendo-se onde estão e quais os procedimentos a serem seguidos. Desta } \\
\text { forma é possível identificar cada processo e recuperá-lo quando necessário permitindo uma } \\
\text { diminuição dos problemas de acesso aos mesmos. }\end{array}$ \\
\hline
\end{tabular}

Fonte: Dados da pesquisa (2018). 
Quadro 2 - Processo da gestão documental na arquivística

(continuação)

\begin{tabular}{|c|l|}
\hline Docente & \multicolumn{1}{c|}{ Entendimento } \\
\hline D3 & $\begin{array}{l}\text { Tenho observado que, atualmente, a gestão de documentos tem suas instâncias teórica e } \\
\text { prática em dois ambientes: o analógico e o digital. Em ambos a gestão de documentos é peça } \\
\text { fundamental para o apoio à administração, aos dados abertos, à transparência pública e se } \\
\text { bem feita consegue cumprir bem a função de garantir a preservação da memória quer seja } \\
\text { nos documentos de suporte analógico, quer seja digital. }\end{array}$ \\
\hline D4 & $\begin{array}{l}\text { Por se tratar de um conjunto de atividades, que são essenciais no processo de gestão, os ar- } \\
\text { quivos públicos e privados vêm ao longo dos anos direcionando suas atividades administrati- } \\
\text { vas com foco na organização dos arquivos, com vistas, a melhor qualidade dos serviços pres- } \\
\text { tados a sociedade por garantir acesso e uso as informações, tanto aos usuários internos quan- } \\
\text { to aos externos. Neste sentido, várias etapas que compõem a gestão se tornam importantes } \\
\text { como a classificação, avaliação e descrição documental. }\end{array}$ \\
\hline
\end{tabular}

Fonte: Dados da pesquisa (2018).

Percebe-se, a partir das respostas, que os docentes compreendem a gestão documental de modo sistêmico; o fluxo informacional, quando bem executado, facilita o acesso à informação, e, consequentemente, a tomada de decisões. Diante deste cenário, enfatiza-se a teoria das três idades e a necessidade da realização da avaliação documental.

Contudo, no PL no 7.920/2017, há controvérsias e, em alguns pontos, incoerência no estabelecimento de condutas da gestão documental, principalmente nas atividades referentes à avaliação e eliminação. Segundo o projeto lei "o documento não digital que deu origem ao documento digitalizado e armazenado eletronicamente poderá ser eliminado". (BRASIL, 2017).

Defendemos a potencialidade dos documentos digitais, principalmente, no processo de circulação e acesso informacional, contudo, é preciso compreender que ainda estamos buscando as melhores estratégias e ferramentas para lidar com as tecnologias. Deste modo, é extremamente perigoso defender a eliminação dos documentos físicos, sem que seja estabelecido condutas eficazes para essa na nova realidade em que a sociedade está inserida.

Portanto, a Arquivologia necessita rever as suas práticas e teorias diante deste cenário; não é possível simplesmente afirmar que as ações de tratamento são iguais, pois temos realidades e dilemas completamente divergentes. Corroborando com essa perspectiva, Souza (2007) afirma que os documentos arquivísticos digitais precisam de tratamento diferenciado, pois possuem características próprias para a comprovação de sua autenticidade, a qual é ameaçada diariamente pelo ciclo acelerado da obsolescência tecnológica.

Quadro 3 - Diferença entre a gestão do documento analógico e o digital

(continua)

\begin{tabular}{|c|l|}
\hline Docente & \multicolumn{1}{|c|}{ Entendimento } \\
\hline D1 & $\begin{array}{l}\text { Teoricamente seria os mesmos fundamentos, contudo, na pratica há algumas questões que } \\
\text { precisam ser melhor discutidas, como por exemplo, a necessidade de um software que faça } \\
\text { automaticamente a passagem pelas fases. É preciso lembrar que os documentos apresentam } \\
\text { especificidades e que as instituições são dinâmicas, portanto, automatizar o processo de avalia- } \\
\text { cão pode ser perigoso. Além disso, há alguns entraves no que diz respeito as questões de auten- } \\
\text { ticidade e outros fundamentos. }\end{array}$ \\
\hline D2 & $\begin{array}{l}\text { Considero que as funções arquivísticas devam acontecer independentes do suporte. Pois, as } \\
\text { atividades de classificar e avaliar são independentes do suporte do documento. Neste aspecto } \\
\text { é importante destacar que a classificação e a avaliação acontecem no sistema, preferencial- } \\
\text { mente no protocolo quando o documento é capturado pelo software de gestão. }\end{array}$ \\
\hline
\end{tabular}

Fonte: Dados da pesquisa (2018). 
Quadro 3 - Diferença entre a gestão do documento analógico e o digital (continuação)

\begin{tabular}{|c|c|}
\hline Docente & Entendimento \\
\hline D3 & $\begin{array}{l}\text { Sim no que tange às especificidades dos documentos digitais, tais como a forma como são } \\
\text { produzidos, tramitados e preservados. Tais peculiaridades dizem respeito a manutenção da } \\
\text { autenticidade e confiabilidades dos documentos digitais preservados e conservados em reposi- } \\
\text { tórios arquivisticos. }\end{array}$ \\
\hline D4 & $\begin{array}{l}\text { Penso que seria necessário refletir um pouco mais antes de responder essa pergunta. Contudo } \\
\text { posso dizer que em sua essência e propósito a gestão de documentos em ambiente analógico e } \\
\text { digital são as mesmas, porém do ponto de vista de procedimentos existem particularidades e } \\
\text { diferenças um bom exemplo disso está nos debates que envolve o que defendem os pressupos- } \\
\text { tos arquivísticos norte-americano (ciclo vital dos documentos) e os australianos (records conti- } \\
\text { nuum). Vejo que aqui no Brasil essa conversa está bastante atrasada e isso nos impede de } \\
\text { avançar no tratamento e no olhar crítico relativo às formas de gestão dos documentos digitais. } \\
\text { Um bom exemplo está no atual cenário arquivístico das instituições públicas, frente à correla- } \\
\text { ção de forças com as ações governamentais que vem sendo impostas. A comunidade Arquivís- } \\
\text { tica, por não ter se antecipado teoricamente ... está correndo contra o tempo e contra as pres- } \\
\text { sões do governo com medidas arbitrárias relacionadas à "administração sem papel". }\end{array}$ \\
\hline
\end{tabular}

Fonte: Dados da pesquisa (2018).

Os entendimentos dos docentes, como observado no Quadro 3, são muito parecidos ao destacar que os fundamentos são iguais, contudo, comentam que existem especificidades que devem ser levadas em consideração no tratamento e na organização dessas informações.

O PL no 7.920/2017 ignora essas especificidades em vários pontos e naturaliza questões que ainda estão em ampla discussão na Arquivologia e sem consenso entre os pesquisadores, tais como sistemas confiáveis/eficientes, repositórios, autenticidade, eliminação do original e substituição do documento digital.

Quadro 4 - Resoluções vigentes e recomendações do CONARQ sobre documentos digitais

\begin{tabular}{|c|l|}
\hline Docente & \multicolumn{1}{c|}{ Entendimento } \\
\hline D1 & $\begin{array}{l}\text { Nos últimos anos, o CONARQ tem produzido alguns materiais para atender a demanda, con- } \\
\text { tudo, as normas ainda estão bem longe da realidade, é preciso focar na realidade das institui- } \\
\text { ções. O grande problema também, são as recomendações do executivo com os arquivos públi- } \\
\text { cos federais, que vem impondo sistemas que não atendem as necessidades dos órgãos, assim, } \\
\text { é muita informação, para pouca viabilidade. }\end{array}$ \\
\hline \multirow{5}{*}{ D2 } & $\begin{array}{l}\text { As recomendações do CONARQ estão em sintonia com as perspectivas arquivísticas. De acordo } \\
\text { com as preocupações para manutenção das características do documento de arquivo, e das } \\
\text { funções necessárias para o percurso que o documento de arquivo deve ter na instituição. Po- } \\
\text { rém, entre as recomendações do CONARQ e as legislações existem uma certa distância. Pois os } \\
\text { legisladores não procuram as pessoas especialistas e muito menos as instituições especializa- } \\
\text { das para elaborarem leis sobre e para os arquivos. }\end{array}$ \\
\hline D3 & $\begin{array}{l}\text { São relevantes contribuições teóricas e técnicas para o tratamento de documentos digitais. } \\
\text { Embora a tentação de dizer que as ações do CONARQ são insuficientes pois o cenário é uma } \\
\text { boa representação disso. Volto atrás e percebo que o contexto político não favorece, em nada, } \\
\text { o CONARQ, menos ainda o Arquivo Nacional e isso compromete o andamento do SIGA e das } \\
\text { Câmaras Técnicas, dentre outros desgastes e morosidades. É necessário muita atenção e en- } \\
\text { volvimento coletivo e associativo da comunidade arquivística para essa situação. O contexto } \\
\text { político, no Brasil e no mundo, está bastante complexo... ao mesmo tempo que órgãos de } \\
\text { controle no âmbito, nacional e internacional pressionam para um lado os governos com inte- } \\
\text { resses duvidosos estão enredando uma trama de interesses que inviabilizam as ações arquivís- } \\
\text { ticas comprometidas com a transparência pública e a preservação ao longo do tempo. }\end{array}$ \\
\hline D4
\end{tabular}

Fonte: Dados da pesquisa (2018). 
Alguns desses assuntos já começam a ser delineados em documentos produzidos pelo CONARQ, portanto, vejamos a posição dos docentes quanto a essas questões, no Quadro 4.

Os docentes ressaltam que, apesar de o CONARQ apresentar relevantes contribuições, as resoluções precisam estar mais próximas das realidades institucionais, apresentando mais detalhadamente os elementos necessários para que o fluxo documental de fato aconteça sem entraves, e que haja certo entrosamento das normas impostas com o poder público federal.

A maioria das instituições não possui mecanismos mínimos para criar um ambiente propício à preservação digital, e, menos ainda, para desenvolver ações eficientes de gestão. Portanto, antes de impor qualquer legislação, o poder público precisa fornecer subsídios (materiais e intelectuais) para que as estratégias de substituição do físico para o digital ocorram em segurança. A falta dessa estruturação irá incorrer no apagamento da nossa memória, pois a digitalização, em si, não significa acesso.

Ampliando essa discussão, Tavares (2012, p. 13) afirma:

[...] os conteúdos informacionais digitais, para que venham a se constituir em referências de sua época, dependerão não só dos métodos de análise vinculados a saberes específicos para sua interpretação ou decodificação, mas dependerão também de estratégias continuadas que garantam a legibilidade futura de dados diante do caráter de superação acelerada das tecnologias. É nesse cenário que emerge o problema da preservação digital e sua relação com a memória e a história.

Buscando compreender o contexto das instituições brasileiras e a dificuldade de aplicar o PL 7.920/2017, iniciamos o segundo bloco de questões.

Quadro 5 -Políticas de preservação para dar suporte à execução do PL no 7.920/2017

\begin{tabular}{|c|l|}
\hline Docente & \multicolumn{1}{c|}{ Entendimento } \\
\hline D1 & $\begin{array}{l}\text { Infelizmente as instituições ainda não estão preparadas para trabalhar com documentos digi- } \\
\text { tais, não há suporte, não há tecnologia, não há repositórios confiáveis, não há políticas de } \\
\text { preservação digital e não há capacitação suficiente para os profissionais. }\end{array}$ \\
\hline D2 & $\begin{array}{l}\text { O referido PL não possui nenhuma base nas especificações da Arquivística, assim o projeto } \\
\text { sendo aprovado trará enormes dificuldades, pois as instituições não estão preparadas para } \\
\text { realizar as atividades necessárias para uma correta digitalização do seu acervo. O que incorre- } \\
\text { rá em completa destruição de documentos sem nenhum processo de avaliação. }\end{array}$ \\
\hline D3 & $\begin{array}{l}\text { Existem estratégias e políticas de preservação digital debatidas e publicadas por estudiosos da } \\
\text { área que contribuem para o tratamento de documentos digitais. }\end{array}$ \\
\hline D4 & $\begin{array}{l}\text { Na verdade, reforço o que respondi anteriormente, faltam discussões e reflexões a esse respei- } \\
\text { to. O cenário político desfavoreceu muito a comunidade arquivistica como um todo. Acredito } \\
\text { que se tivéssemos tido a oportunidade de dar continuidade à Conferência Nacional dos Arqui- } \\
\text { vos, assuntos dessa natureza e gravidade teriam outras proporções. }\end{array}$ \\
\hline
\end{tabular}

Fonte: Dados da pesquisa (2018).

No Quadro 5, observa-se que todos os docentes ressaltaram a importância das políticas de preservação nos arquivos digitais. A falta destas estratégias deixará os acervos suscetíveis a vários riscos, inclusive, à perda do acesso a esses documentos.

Corroborando com essa perspectiva, Silva Júnior e Mota (2012) ressaltam que a política de preservação deve ser planejada de acordo com a política administrativa, implementando ações de preservação dos acervos de modo que o acesso seja permanente. Portanto, sem os elementos que garantam a manutenção dos repositórios digitais, sem capacitação 
dos profissionais e sem estratégias pontuadas na política, se torna quase impossível garantir o acesso e a conservação do documento digital.

O Projeto Lei $\mathrm{n}$ 0 7.920/2017 trata em alguns artigos da necessidade de garantir a segurança e a preservação das informações digitais, contudo, aponta que deverão ser pensadas futuramente com um regulamento próprio. O grande problema é que, conforme as respostas da maioria dos docentes, falta estrutura nas instituições para a realização de políticas de preservação e, assim, incorremos no risco de perder futuramente as informações digitais. Corroborando com essa perspectiva, Lurdes Saramago (2002, p. 55) afirma: "Os recursos digitais são especialmente vulneráveis por estarem armazenados em suportes magnéticos ou ópticos frágeis. Os recursos digitais tornam-se ilegíveis e inacessíveis se os mecanismos de leitura necessários se tornarem obsoletos.".

Diante deste cenário, é importante procurar compreender a visão dos docentes quanto aos impactos efetivos do PL, caso seja aprovado, conforme Quadro 6.

Quadro 6 - Impactos práticos do PL na rotina das instituições

\begin{tabular}{|c|l|}
\hline Docente & \multicolumn{1}{c|}{ Entendimento } \\
\hline D1 & $\begin{array}{l}\text { Irá gerar um caos, visto que não há estrutura para atender essa demanda, o que trará inúme- } \\
\text { ras consequências para a memória institucional e social. }\end{array}$ \\
\hline D2 & $\begin{array}{l}\text { A destruição sem nenhum cuidado dos documentos em prol do espaço físico para outras fun- } \\
\text { ções das instituições, pois cada uma poderá eliminar sem nenhum critério específico de profis- } \\
\text { sionais da área da Arquivologia. Também ampliará o processo de corrupção, tendo em vista } \\
\text { que, com a eliminação dos originais em suporte físico os representantes digitais passam a ser } \\
\text { as únicas referências da informação e se foi produzido a partir de falsidade dos originais isto } \\
\text { não poderá mais ser comprovado. }\end{array}$ \\
\hline D3 & $\begin{array}{l}\text { Será de gestão de documentos híbridos como também se chama a atenção de se considerar } \\
\text { cópia de representante digital como original. Dessa forma, configura-se uma fragilidade di- } \\
\text { plomática ao documento eletrônico oriundo de original convencional. }\end{array}$ \\
\hline D4 & $\begin{array}{l}\text { As perspectivas são péssimas, uma das principais é o risco de se perder a memória. A } \\
\text { PL7920/2017 é um erro para o futuro é um descaso com o presente acervo já preservado ana- } \\
\text { logicamente. Um retrocesso, pois, seus argumentos de economicidade não se sustentam e só } \\
\text { trazem prejuízos para a memória nacional. }\end{array}$ \\
\hline
\end{tabular}

Fonte: Dados da pesquisa (2018).

As respostam convergem para o entendimento de que o caos estaria instaurado caso o PL venha a ser aprovado, visto que a eliminação do documento original ocasionará a perda da memória institucional/social e possibilita um aumento da corrupção, uma vez que os documentos digitais podem ser facilmente alterados de acordo com a necessidade dos parlamentares.

Nesse sentido, Santos e Flores (2015, p. 213) comentam:

Considerando que os documentos arquivísticos têm função probatória e informativa, a perda de sua confiabilidade implica na perda do sentido da existência destes documentos. Por estas razões, os sistemas de gestão e preservação devem oferecer mecanismos para verificação constante de sua integridade e autenticidade, o que irá gerar confiança ao público alvo.

Temos ciência da importância da tecnologia e as potencialidades em seu uso, contudo, antes de implementar legislações que visem à substituição do físico pelo digital é fundamental estruturar as instituições de modo que a preservação ocorra como um imperativo. "Para preservar os documentos digitais de uma instituição é preciso planejamento, ou seja, inicialmente devem ser definidas as políticas de preservação digital." (SANTOS; FLORES, 
2015, p. 212). O PL no 7.920/2017 só poderia ser executado, após o estabelecimento das resoluções de preservação digital e a estruturação mínima das instituições.

Um dos grandes problemas para a eficiência, na aplicação de legislações no Brasil, é que os nossos governantes têm o ímpeto de pensar na consequência fim, e ignorar as estratégias para efetivar a ação. Isso nos leva a ter muitas leis, porém, pouca aplicação. Assim, é preciso repensar o PL no 7.920/2017, antes de sua aprovação, visto que a sua viabilidade depende de um planejamento amplo nas políticas arquivísticas institucionais.

Além disso, buscamos compreender os aspectos de originalidade do documento digital, conforme Quadro 7.

Quadro 7 - Originalidade do documento digital com a aplicação do PL no 7.920/2017

\begin{tabular}{|c|c|}
\hline Docente & Entendimento \\
\hline D1 & $\begin{array}{l}\text { A partir da PL, documento digitalizado terá o mesmo valor que o papel, não fica evidente na } \\
\text { lei, a questão da originalidade. Ainda não há uma legislação que reconheça o documento } \\
\text { digitalizado como original. }\end{array}$ \\
\hline D2 & $\begin{array}{l}\text { Existe sim legislação sobre o documento digitalizado. Mas os atuais marcos legais não permi- } \\
\text { tem a destruição dos físicos. }\end{array}$ \\
\hline D3 & $\begin{array}{l}\text { No contexto da PL o documento digitalizado terá o mesmo efeito do original. No que se refere } \\
\text { a legislação que reconheça o documento digitalizado como original não há. Na Lei no } \\
12.682 / 2012 \text { no seu art. 3o diz que: } \\
\text { Art. } 3 \text { o O processo de digitalização deverá ser realizado de forma a manter a integridade, a } \\
\text { autenticidade e, se necessário, a confidencialidade do documento digital, com o emprego de } \\
\text { certificado digital emitido no âmbito da Infraestrutura de Chaves Públicas Brasileira - ICP - } \\
\text { Brasil. } \\
\text { Com isso, verifica-se a preocupação em prover ao representante digital de segurança da in- } \\
\text { formação com o emprego da certificação digital. O que aufere respaldo legal de fé pública } \\
\text { conforme o texto do art. } 10, \text { da MP } n^{\circ} 2.200-2 \text {, os documentos eletrônicos assinados digital- } \\
\text { mente com o uso de certificados emitidos no âmbito da ICP-Brasil têm a mesma validade jurí- } \\
\text { dica que os documentos em papel com assinaturas manuscritas. Importante frisar que os do- } \\
\text { cumentos eletrônicos assinados digitalmente por meio de certificados emitidos fora do âmbito } \\
\text { da ICP-Brasil também têm validade jurídica, mas esta dependerá da aceitação de ambas as } \\
\text { partes, emitente e destinatário, conforme determina a redação do § } 20 \text { do art. } 10 \text { da MP } n^{\circ} \\
2.200-2 \text {. }\end{array}$ \\
\hline D4 & Não respondeu à pergunta. \\
\hline
\end{tabular}

Fonte: Dados da pesquisa (2018).

As respostas apresentam diferentes perspectivas sobre a existência de legislações que respaldam os documentos digitalizados, visto que há uma grande confusão no entendimento de originalidade do documento digital.

Existem, atualmente, no Brasil, várias discussões sobre a questão supracitada, contudo, não há um consenso sobre a atribuição de originalidade, o que temos é uma discussão sobre a atribuição de confiabilidade e autenticidade. As normas brasileiras determinam, de modo geral, que documentos criados a partir de reprodução (digitalizados, fotocopiados e etc.) devem apresentar assinatura de uma pessoa com fé pública ou certificação digital para que tenha a mesma força probante do original, ou seja, para que tenha credibilidade e aceito por sua autenticidade.

O PL no 7.920/2017 estabelece que o documento digitalizado produzido a partir do processo de digitalização terá o mesmo valor legal, para todos os fins de direito, do documento não digital que the deu origem, assegurando, assim, a eliminação do original sem prejuízo. Contudo, no art. 2ํㅡ, segundo parágrafo, o PL pondera que "[...] o valor probatório do 
documento digitalizado não se aplica ao documento cujo porte ou apresentação sejam exigidos por lei." (BRASIL, 2017).

Nesse contexto, faz-se necessário compreender como ocorrerá a aplicação da Tabela de Temporalidade (TTD) frente à eliminação do documento analógico.

Quadro 8 - Aplicação da Tabela de Temporalidade a documentos digitais

\begin{tabular}{|c|c|}
\hline Docente & Entendimento \\
\hline D1 & $\begin{array}{l}\text { A PL não evidencia nenhuma questão sobre a TTD, contudo, ao estabelecer o mesmo valor } \\
\text { entre os documentos físicos e digitais, certamente a eliminação do original irá ocorrer sem } \\
\text { atender os preceitos da TTD. }\end{array}$ \\
\hline D2 & $\begin{array}{l}\text { Esta é uma grande confusão. O PL diz que os documentos permanentes não poderão ser elimi- } \\
\text { nados, porém a maioria das instituições sejam públicas ou privadas não possuem tabelas de } \\
\text { temporalidades. Então como saber se o documento é permanente ou não? Este instrumento } \\
\text { de gestão é um ilustre desconhecido para a maioria das entidades, que não sabem o ele são e } \\
\text { muito menos como fazer uma tabela. }\end{array}$ \\
\hline D3 & $\begin{array}{l}\text { No texto ela diz o seguinte: Parágrafo único. O documento não destinado à guarda permanen- } \\
\text { te poderá, na forma de regulamento, ser eliminado quando digitalizado conforme processo de } \\
\text { digitalização previsto em regulamento. (NR) } \\
\text { Com isso deduz-se que todos os documentos digitalizados devem ser preservados independen- } \\
\text { temente de prazo de guarda. }\end{array}$ \\
\hline D4 & $\begin{array}{l}\text { Se vocês estão se referindo ao "Código de Classificação e a Tabela de Temporalidade e Desti- } \\
\text { nação de Documentos de Arquivo relativos às atividades-meio da Administração Pública Fede- } \\
\text { ral". Posso dizer que esse instrumento não faz distinção entre o digital e o analógico. E por ter } \\
\text { sido elaborado antes dessa polêmica, obviamente, este instrumento não está preparado para } \\
\text { essa realidade. Carece atualizações e adaptações sob esses aspectos e outros problemas de } \\
\text { cunho diplomático, estrutural, etc. }\end{array}$ \\
\hline
\end{tabular}

Fonte: Dados da pesquisa (2018).

Segundo Santos (2014), a TTD é o instrumento que faz parte das atividades da gestão, que realiza a simplificação e a racionalização dos procedimentos de gestão documental, proporcionando maior agilidade e precisão na recuperação dos documentos e das informações, autorizando a eliminação criteriosa de documentos cujos valores já se esgotaram. Contudo, conforme destaca D2, a maioria das organizações não possui TTD, então, torna-se impossível caracterizar o valor permanente dos documentos. D1 ressalta que o PL não menciona a TTD, em seu texto, e D4 ressalta que a mesma carece de atualizações.

O D3 trouxe uma passagem do PL no 7.920/2017 que atualiza a Lei $n=8.159$, de 8 de janeiro de 1991, uma vez que as leis vigentes também necessitam ser atualizadas para que tenham vinculação na sua aplicação. Contudo, no PL em questão, fica evidente que os documentos não digitais, inclusive em tramitação, que deram origem ao documento digitalizado podem ser eliminados.

Nesse sentido, perguntamos aos docentes acerca da preparação das instituições para atender ao PL.

Quadro 9 - Condições das instituições para atender ao PL no 7.920/2017 (continua)

\begin{tabular}{|c|l|}
\hline Docente & \multicolumn{1}{|c|}{ Entendimento } \\
\hline \multirow{5}{*}{ D1 } & $\begin{array}{l}\text { Não. A PL vai ocasionar um caos nas instituições... Os gestores vão mandar eliminar a docu- } \\
\text { mentação sem respeito a legislação arquivística, teremos problemas na formação de arquivos } \\
\text { permanentes, sem a tecnologia adequada, não conseguiremos realizar gestão e nem a preser- } \\
\text { vação digital, enfim... Ainda não estamos preparados para a PL. O grande problema é que mui- } \\
\text { tas vezes, tendem a implementar a Lei, para depois pensar na estrutura de funcionamento. }\end{array}$ \\
\hline
\end{tabular}

Fonte: Dados da pesquisa (2018). 
Quadro 9 - Condições das instituições para atender ao PL no 7.920/2017 (continuação)

\begin{tabular}{|c|l|}
\hline Docente & \multicolumn{1}{c|}{ Entendimento } \\
\hline D2 & $\begin{array}{l}\text { Este é outro problema. O processo de digitalização não é apenas pegar documentos e passar por } \\
\text { mecanismo de escaneamento. Existem critérios que devem ser estabelecidos, além o preço para } \\
\text { fazer ou contratar serviços de digitalização poder ser desencorajador para algumas instituições. } \\
\text { Não podemos esquecer que após a digitalização o projeto não prevê o armazenamento das } \\
\text { imagens. Assim, as empresas não tem a menor noção de como armazenar estes representantes } \\
\text { digitais que precisariam de um repositório arquivistico confiável. }\end{array}$ \\
\hline D3 & $\begin{array}{l}\text { No que se refere ao processo de digitalização vai depender de recursos financeiros, tecnológicos } \\
\text { e de pessoal que cada Instituição dispor. Enquanto à preservação digital, na minha opinião a } \\
\text { maioria das Instituições desconhecem dos procedimentos técnicos necessários para promove- } \\
\text { rem preservação de documentos digitais. }\end{array}$ \\
\hline D4 & \begin{tabular}{l} 
Não. \\
\hline
\end{tabular}
\end{tabular}

Fonte: Dados da pesquisa (2018).

Como se pode observar no Quadro 9, todas as respostas convergem para a afirmativa que as instituições não estão preparadas para atender ao que o PL no 7.920/2017 determina. Problemas como recursos financeiros, capacitação de pessoal, confiabilidade e manutenção dos repositórios foram os mais citados entre os docentes.

Diante desta realidade, procuram compreender qual o posicionamento dos docentes sobre a PL 7.920/2017.

Quadro 10 - Posicionamento docente em relação ao PL no 7.920/2017

\begin{tabular}{|c|l|}
\hline Docente & \multicolumn{1}{c|}{ Entendimento } \\
\hline D1 & $\begin{array}{l}\text { Sou contra! A PL tem vários furos que preocupam o processo de gestão além disso, o documento } \\
\text { digital ainda não é reconhecido como original, devido a facilidade de falsificação e alteração de } \\
\text { dados. Assim, ainda não podemos confiar inteiramente no documento digitalizado. }\end{array}$ \\
\hline D2 & Sou totalmente contrário. \\
\hline D3 & Que essa PL seja arquivada. \\
\hline D4 & $\begin{array}{l}\text { Diante de tudo o que respondi anteriormente, vejo esse projeto de lei como um risco à gestão e } \\
\text { transparência pública e que inviabiliza a preservação da memória ao longo do tempo. }\end{array}$ \\
\hline
\end{tabular}

Fonte: Dados da pesquisa (2018).

Assim como as classes representantes da profissão se manifestaram contrários ao PL no 7.920/2017, os professores também afirmaram não concordar com a sua aprovação. Os motivos são os mais diversos, contudo, destaca-se, sobretudo, o risco do desaparecimento da memória, visto que a falta de estratégias de preservação nas instituições brasileiras, certamente, ocasionará na perda das informações no futuro. Conforme ressaltam Santos e Fores (2015, p. 201), "A preservação de documentos digitais deve ser fundamentada no planejamento, alocação de recursos, aplicação de métodos de conservação e tecnologias necessárias para assegurar as características diplomáticas originais do documento[...]", possibilitando o acesso eficaz e eficiente ao documento.

E, por fim, questionamos sobre os impactos do PL na teoria e prática arquivística, especialmente, no tocante ao princípio de autenticidade.

Como consta no Quadro 11, todos os docentes consideram a PL no 7.920/2017 um texto falho com graves lacunas ao considerar que uma cópia autenticada possa substituir o original, além disso, em nenhum momento foi pensada de modo a contemplar as normas arquivísticas e de gestão. Portanto, o PL supracitado é uma proposta falha e que contempla meramente a destruição dos arquivos originais pela substituição caótica de documentos digitalizados. 
Quadro 11 - Impactos do PL no 7.920/2017 nas teorias e práticas Arquivísticas

\begin{tabular}{|c|l|}
\hline Docente & \multicolumn{1}{c|}{ Entendimento } \\
\hline D1 & $\begin{array}{l}\text { Terá um grande impacto! É preciso amadurecer a PL de acordo com a legislação arquivística e } \\
\text { ouvir os profissionais de arquivo para que todos os princípios e técnicas sejam contempladas }\end{array}$ \\
\hline D2 & $\begin{array}{l}\text { Extremamente danoso para a Arquivística e principalmente para a manutenção da autentici- } \\
\text { dade. Como disse anteriormente, a digitalização de documentos falsos pode ser uma realidade } \\
\text { nas instituições. Além disso, a maior parte destas instituições por não possuírem arquivistas } \\
\text { não realizariam o mínimo necessário para a manutenção e preservação dos documentos e com } \\
\text { isso a perda de informações será catastrófico para o estado e os cidadãos. }\end{array}$ \\
\hline D3 & $\begin{array}{l}\text { Os impactos são bastante sérios e prejudiciais a presunção de autenticidade de documentos } \\
\text { digitais ao considerar uma cópia autenticada como original. }\end{array}$ \\
\hline D4 & $\begin{array}{l}\text { Esse projeto de lei é totalmente equivocado em todos os princípios arquivísticos. Compromete } \\
\text { não apenas a autenticidade, mas todos os demais fundamentos e princípios da área. Esses } \\
\text { equívocos estão tanto no âmbito dos documentos digitais como no âmbito dos documentos } \\
\text { analógicos (legado). }\end{array}$ \\
\hline
\end{tabular}

Fonte: Dados da pesquisa (2018).

\section{CONSIDERAÇÕES FINAIS}

Após a realização da pesquisa, reafirma-se a falta de diretrizes para a implementação do PL no 7.920/2017. A substituição de documentos analógicos por digitais não resolverá os problemas de organização das massas documentais nas instituições, e, dificilmente, facilitará o acesso. A eficiência de acesso é dada a partir do momento em que se tem estratégias eficientes para a recuperação informacional. Além disso, é preciso acompanhar a obsolescência das tecnologias, visto que a sua atualização é extremamente dinâmica.

No último ano, pouco foi discutido sobre esse PL, visto que o processo não teve encaminhamento relevante na Câmara dos Deputados, nesse período. Contudo, essa discussão não pode ficar adormecida, uma vez que a qualquer momento esse assunto pode voltar à tona e precisamos estar preparados para lutar contra essa situação. Vale salientar, que a pressão popular em 2017 foi tão grande que o propositor do PL chegou a pedir o seu arquivamento, porém, a proposta continua tão viva que, em 30 de abril 2019, o Presidente da República concedeu o direito à eliminação de documentos originais, após a digitalização, para empresas e acervos privados.

Neste ínterim, precisamos continuar refletindo sobre esse novo cenário ao qual estamos sendo submetidos e pensar como nós, Arquivistas, podemos contribuir para que a memória seja preservada. Os arquivos são provas fiéis dos acontecimentos passados que embasam prospecções futuras da sociedade, e que garantem direitos e reforçam culturas e identidades. Portanto, não podemos nos calar; é preciso que os profissionais se unam em defesa do direito à memória salvaguardada nos documentos arquivísticos.

\section{REFERÊNCIAS}

ANGELONI, M. T. et al. Organizações do conhecimento: infra-estrutura, pessoas e tecnologia. Rio de Janeiro: Saraiva, 2002.

ARAÚJO, M. C. F. O papel do Arquivista na gestão eletrônica de documentos: uma análise do instituto de previdência do município de João pessoa. 2016. 5 f. Trabalho de Conclusão de Curso (Graduação) - Curso de Arquivologia, Universidade Estadual da Paraíba, João Pessoa, 2016. 
ARQUIVO NACIONAL. Dicionário brasileiro de terminologia arquivística. Rio de Janeiro: Arquivo Nacional, 2005. 232 p. Disponível em:

http://www.arquivonacional.gov.br/Media/Dicion\%20Term\%20Arquiv.pdf. Acesso em: 10 out. 2018.

ASSOCIAÇÃO BRASILEIRA DE EDUCAÇÃO EM CIÊNCIA DA INFORMAÇÃO (ABECIN). Manifesto da ABECIN. 2017.

BERNARDES, I. P.; DELATORRE, H. Gestão documental aplicada. São Paulo: Arquivo Público do Estado de São Paulo, 2008. Disponível em:

http://www.arquivoestado.sp.gov.br/site/assets/publicacao/anexo/gestao documental aplicada.pd f. Acesso em: 21 jul. 2018.

BRASIL. Câmara dos Deputados. Projeto de Lei no 7.920/2017. Altera a Lei no 12.682, de 9 de julho de 2012, a Lei no 8.159, de 8 de janeiro de 1991, o Decreto-Lei no 3.689, de 3 de outubro de 1941 (Código de Processo Penal), a Lei no 12.865, de 9 de outubro de 2013, e a Lei $n=13.105$, de 16 de março de 2015 (Código de Processo Civil), para dispor sobre a digitalização de documentos. Disponível em:

https://www.camara.leg.br/proposicoesWeb/prop mostrarintegra?codteor=1583373\&filename=Des pacho-PL+7920/2017-07/08/2017. Acesso em: 20 jul. 2018.

BRASIL. Presidência da República. Lei no 13.874, de 2019. Institui a Declaração de Direitos de Liberdade Econômica; estabelece garantias de livre mercado; altera as Leis nos 10.406, de 10 de janeiro de 2002 (Código Civil), 6.404, de 15 de dezembro de 1976, 11.598, de 3 de dezembro de 2007, 12.682, de 9 de julho de 2012, 6.015, de 31 de dezembro de 1973, 10.522, de 19 de julho de 2002, 8.934, de 18 de novembro 1994, o Decreto-Lei no 9.760, de 5 de setembro de 1946 e a Consolidação das Leis do Trabalho, aprovada pelo Decreto-Lei no 5.452, de 1 ㅇ de maio de 1943; revoga a Lei Delegada $n$ ㅇ 4, de 26 de setembro de 1962, a Lei no 11.887, de 24 de dezembro de 2008, e dispositivos do Decreto-Lei no 73, de 21 de novembro de 1966; e dá outras providências. Brasília, 20 set. 2019. Disponível em:

http://www.planalto.gov.br/ccivil 03/ ato2019-2022/2019/lei/L13874.htm. Acesso em: 15 abr. 2019

CRUZ, C.; RIBEIRO, U. Metodologia científica: teoria e prática. Rio de Janeiro: Axcel, 2004.

FACHIN, J. Gerenciamento Eletrônicos de Documentos na Universidade Federal de Santa Catarina. 2010. 80 f. TCC (Graduação) - Curso de Biblioteconomia, Universidade Federal de Santa Catarina, Florianópolis, 2010.

FARIA, W. S. A normalização dos instrumentos de gestão arquivística no Brasil: um estudo da influência das resoluções do CONARQ na organização dos arquivos da Justiça Eleitoral Brasileira. Dissertação (Mestrado em Ciência da Informação) - Faculdade de Economia, Administração, Contabilidade e Ciência da Informação e Documentação. Departamento de Ciência da Informação e Documentação da Universidade de Brasília (UnB), Brasília, 2006. Disponível em: https://repositorio.unb.br/handle/10482/2757?mode=full. Acesso em: 22 ago. 2018. 
GRÁCIO, J. C. A. Preservação digital na gestão da informação: um modelo processual para as instituições de ensino superior. São Paulo: Cultura Acadêmica, 2012.

HOTT, D. F. M.; CRUZ-RIASCOS, S. A. Preservação documental de documentos arquivísticos e o Projeto de Lei 7.920/2017 sob a ótica da Ciência da Informação. RICl: revista Iberoamericana de Ciência da Informação, Brasília, v. 11, n. 1, p. 274-299, jan./abr. 2018. Disponível em: https://periodicos.unb.br/index.php/RICl/article/view/8571/7141. Acesso em: 22 ago. 2018.

$\mathrm{KOCH}, \mathrm{W}$. W. Gerenciamento eletrônico de documentos: conceitos, tecnologias e considerações gerais. São Paulo: CENADEM, 1997. 147 p.

QUEIMA de Arquivo não. 2017. Disponível em: https://queimadearquivonao.webnode.com/. Acesso em: 15 maio 2018.

SANTOS, E. G. O gerenciamento documental do Arquivo Central da Universidade Federal de Sergipe. 2014. 82f. Monografia (Graduação em Biblioteconomia e Documentação) - Universidade Federal de Sergipe, Aracajú, 2014.

SANTOS, H. M.; FLORES, D. Repositórios digitais confiáveis para documentos arquivísticos: ponderações sobre a preservação em longo prazo. Perspectivas em Ciência da Informação, v. 20, n. 2, p. 198-218, abr./jun. 2015. Disponível em:

http://portaldeperiodicos.eci.ufmg.br/index.php/pci/article/view/2341/1604. Acesso em: 15 maio 2018.

SARAMAGO, M. L. Preservação digital a longo prazo: boas práticas e estratégias. Cadernos BAD, Lisboa, n. 2, p. 54-68, 2002. Disponível em:

https://www.bad.pt/publicacoes/index.php/cadernos/article/view/866/865. Acesso em: 15 maio 2018.

SILVA JÚNIOR, L. P.; MOTA, V. G. Políticas de preservação digital no Brasil: características e implementação. Ciência da Informação, Brasília, v. 14, n. 1, p. 51-64, jan./abr., 2012. Disponível em: http://revista.ibict.br/ciinf/article/view/1351. Acesso em: 25 ago. 2018.

TAVARES, M. F. D. Preservação digital: entre a memória e a história. Ciência da Informação, Brasília, v. 41, n. 1, p.9-21, jan./abr., 2012. Disponível em:

http://revista.ibict.br/ciinf/article/view/1348/1527. Acesso em: 25 ago. 2018 